\title{
An Intelligent Tender Evaluation System using Evidential Reasoning Approach
}

\author{
Md. Shahadat Hossain \\ Professor \\ Dept. of CSE \\ University of Chittagong
}

\author{
Md. Salah Uddin Chowdury \\ Lecturer \\ Dept. of CSE \\ BGC Trust University Bangladesh
}

\author{
Smita Sarker \\ Lecturer \\ Dept. of CSE \\ BGC Trust University Bangladesh
}

\begin{abstract}
Tender evaluation is a critical decision making process that has a great impact on the project performance, with regards to time, cost and quality. The selection of the appropriate tender can ensure a smooth finishing of a project and eliminate several problems during construction. In this paper, the evidential reasoning (ER) approach which is capable of processing both quantitative and qualitative data is applied as a means of addressing the tender evaluation process. The process of building a multiple criteria decision model of a hierarchical structure of a tender is presented, in which both quantitative and qualitative information is represented in a unified manner. At the light of a case study of Bangladesh the tender evaluation process is then fully investigated using the ER approach. The advantages of applying this model in practice and its analysis are discussed.
\end{abstract}

\section{Keywords}

Construction, decision-maker, evidential reasoning, multiple criteria decision analysis, tender evaluation.

\section{INTRODUCTION}

Tendering is a critical activity in a capital works project and is normally the accepted means of obtaining a fair price and best value for undertaking construction works[1][2][13]. The tender process involves a principal of seeking competitive bids for works and/or services that are set out in tender documents typically which include contract conditions, specifications and drawings or a documented brief. Offers are made by a variety of bidders (e.g. contractors, consortia and/or consultants) who set out their offer in a submission in accordance with the tendering requirements. The introduction of quality into the evaluation of tender offers provide a viable means of managing the risk of non-conformance and the failure to attainment project outcomes, without violating the principles of fairness, transparency and value for money, particularly in respect of professional service contracts.

Tendering falls under the oversight of a governance group. Local governments usually organize tenders where local companies bid for large scale projects supported and financed by the government. Tenders involve large amounts of money. Since the government supports the projects, on one side the companies find it very prestigious to be part of it, and on the other side, the public is very sensitive about how well the money is used. A multi-disciplinary committee is constituted in order to evaluate the participants. The evaluation process consists of two phases: first is the pre-qualification phase where tenders are scrutinized based on their legal and technical system, and second is the final phase where tenders are evaluated based on a costs/performance analysis [1]. In the first phase, participants submit general information about the company, their legal and technical system, number of employees, etc. In the second phase, participants submit information on prices and product quality. The companies are then evaluated based on the criterions such as price, product quality, and technical competence [1] [2].

To assess tenders, a system of criteria intended to encapsulate the competence of the tendering organization to undertake a particular project is used to rate the renderer's bids. Selection criteria are intended to assess the competence of the tendering organizations to achieve the required project outcome [1].

The criteria are usually selected from the following:

- Relevant experience;

- Appreciation of the task;

- Past performance;

- Management and technical skills;

- Resources;

- Management systems;

- Methodology; and

- Price.

Selection of above qualititative and quantitative criteria which reflect the critical elements of the project and that can be assigned a weighting to reflect the relative importance of selection criteria. Then scores that are based on information submitted with the tender bid; and normalizing the non-price criteria and the tender price before applying the weightings to allow for the true effect and advantage of the weighting system[1][2][13].

The main objective of this paper is to select best tender using Evidential Reasoning approach by aggregating significant factors of selected criteria. Finally we show the ranking of evaluated tender.

In this paper, ER approach will be applied by taking factors considered in evaluating tender of a government organization of Bangladesh, named Local Government Engineering Department (LGED). In evaluating tender, LGED mainly considers factors such as relevance experience, past performance, technical skills, management system of the Bidder Company, and price [14],[15],[16]. Each of the factors again consists of sub-factors and hence they are organized in a hierarchical order, which has been illustrated in Figure 1. It can be seen that the factors mentioned are of both qualitative and quantitative nature. These qualitative factors are the source of uncertainty and this will be addressed by using ER approach as will be elaborated in sections 3 and 4 . Hence, the application of ER approach for tender evaluation in the 
context of Bangladesh will ensure the transparency and hence, will mitigate corruption and criticism significantly.

We organize the research activities as follows. In section 2 we present the related works respectively. The ER approach for tender evaluation is outlined and illustrated by sections 3 . The experimental result is outline by section 4.Finaly we concluding our remarks at section 5 in which we show the outcomes of evaluation with the discussion of suggestion of future work.

\section{RELATED WORKS}

There are a variety of different methods that can be employed to select which contractor should be awarded a tender but research conducted for this project has indicated that the most commonly used are:

1) Bespoke approaches, which are widely used in industry and are selection procedures that are developed by individual organisations so there are many variations and relies purely yes/no criteria and the decision maker's judgement. This process is very subjective and is more susceptible to the biases of the decision maker [10][11].

2) Multi-criteria selection methods which use weighted nonprice factors as well as price in either a single or two-stage (i.e. prequalification) selection process. This approach reduces the impact of the biases of the decision maker by determining the weighting of each criterion prior to viewing any submissions [13].

But the above processes do not handle uncertainty of both qualitative and quantitative data. But the Evidential Reasoning is the strong method for handling such kind of uncertainty.

\section{THE EVIDENTIAL REASONING APPROACH FOR TENDER EVALUATION}

\subsection{Identification of Evaluation Factors and Evaluation Grades}

We apply the evidential reasoning approach to analyze the performance of four types of tender including Tenderl, Tender2, Tender 3 , and Tender4. Here both qualitative and quantitative performance attributes are considered for demonstrating purpose. The major performance attributes are considered as relevant experience, past performance, technical skills, management systems and price. For facilitating the assessment these attributes are further classified basic attributes such as tender role, project cost, project duration, quality standard, target performance, extension of time granted, experience, technical personnel, professional ability, quality system, environmental management system and OHS \& R management System which we shown on the figure 1 .

\subsection{Computational steps of aggregating assessment}

Firstly we show the total calculation for aggregation of the Relevant Experience .For Tender 1 .The Relevant Experience $\left(e_{1}\right)$ is assessed by three basic attributes: tender role $\left(e_{11}\right)$, project cost $\left(\mathrm{e}_{12}\right)$ and project duration $\left(\mathrm{e}_{13}\right)$.

From the table1, we have

$\begin{array}{llll}\beta_{1,1}=0, & \beta_{2,1}=1.0, & \beta_{3,1}=0, & \beta_{4,1}=0 \\ \beta_{1,2}=0, & \beta_{2,2}=0, & \beta_{3,2}=0.7, & \beta_{4,2}=0.3 \\ \beta_{1,3}=0, & \beta_{2,3}=0.2, & \beta_{3,3}=0.6 & \beta_{4,3}=0\end{array}$

On the basis of importance on the tender evaluation suppose the hypothetical weights for three attributes are: $\omega_{11}=0.30$, $\omega 12=0.35$ and $\omega_{12}=0.35$.

Now using expression

$$
m_{n, i}=\omega_{i} \beta_{n, i} \quad n=1, \ldots, N ;
$$

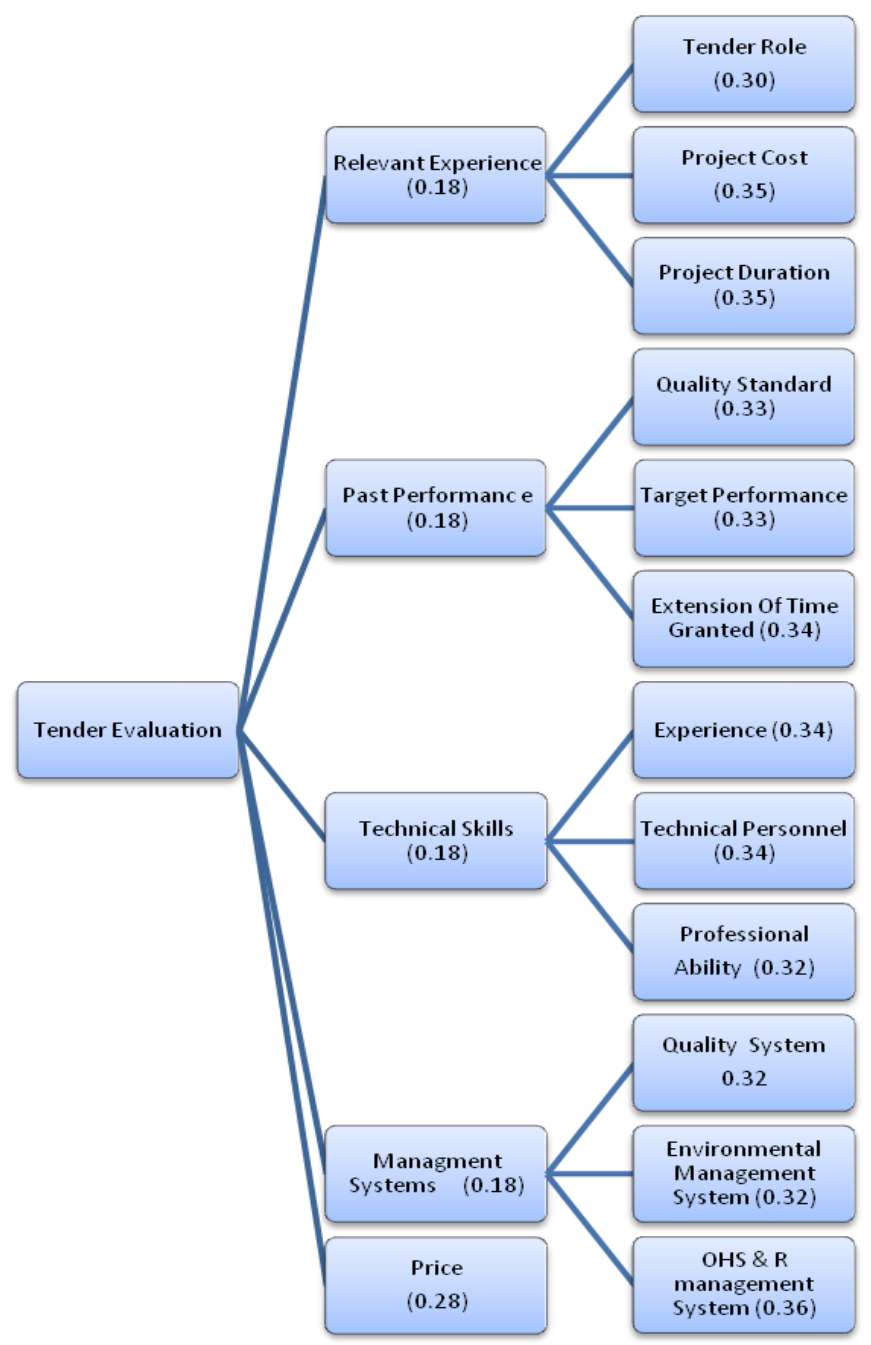

Fig. 1. Evaluation hierarchy of the tender evaluation

we get the basic probability masses $\left(m_{n, i}\right)$ as follows [4], [5], [6], [7], [8]:

$$
\begin{aligned}
& m_{1,1}=0 ; \quad m_{2,1}=0.30 ; \quad m_{3,1}=0 ; \quad m_{4,1}=0 ; \\
& \bar{m}_{H, 1}=0.70 \quad \tilde{m}_{H, 1}=0 \\
& m_{1,2}=0 ; \quad m_{2,2}=0 ; \quad m_{3,2}=0.245 ; \quad m_{4,2}=0.105 ; \\
& \bar{m}_{H, 2}=0.65 ; \tilde{m}_{H, 2}=0 \\
& m_{l, 3}=0 ; \quad m_{2,3}=0.70 ; \quad m_{3,3}=0.105 ; \quad m_{4,3}=0 ; \\
& \bar{m}_{H, 3}=0.65 ; \tilde{m}_{H, 3}=0.07
\end{aligned}
$$

By using recursive equations we get the combined probability masses [4], [5], [6], [7], [8]. Since 


$$
\begin{aligned}
& K_{I(2)}=\left[1-\sum_{t=1}^{4} \sum_{\substack{j=1 \\
j \neq t}}^{4} m_{t, I(1)} m_{j, 2}\right]^{-1} \\
& =[1-(0+. .+0+0.0735+0.0315+0+. .+0)]^{-1} \\
& =[1-0.105]^{-1}=1.1173
\end{aligned}
$$

\begin{tabular}{|c|c|c|c|c|c|c|c|c|c|c|c|c|}
\hline & Weight & \multicolumn{4}{|c|}{ Belief } & \multicolumn{7}{|c|}{ Probability Mass } \\
\hline & $\omega_{1, \mathrm{i}}$ & $\beta_{1, \mathrm{i}}$ & $\beta_{2, \mathrm{i}}$ & $\beta_{3, \mathrm{i}}$ & $\beta_{4, \mathrm{i}}$ & $\mathrm{m}_{1}$ & $\mathrm{~m}_{2, \mathrm{i}}$ & $\mathrm{m}_{3, \mathrm{i}}$ & $\mathrm{m}_{4, \mathrm{i}}$ & $\mathrm{m}_{\mathrm{H}, \mathrm{i}}$ & $\mathrm{m}_{\mathrm{H}, \mathrm{i}}^{-}$ & $\tilde{\mathrm{m}}_{\mathrm{H}}$ \\
\hline $\begin{array}{l}\text { Tender } \\
\text { Role }\end{array}$ & 0.33 & 0 & 1.0 & 0 & 0 & 0 & 0.33 & 0 & 0 & 0.77 & 0.77 & 0 \\
\hline $\begin{array}{l}\text { Project } \\
\text { Cost }\end{array}$ & 0.35 & 0 & 0 & 0.7 & 0.3 & 0 & 0.245 & 0.105 & 0 & 0.65 & 0.65 & 0 \\
\hline $\begin{array}{l}\text { Project } \\
\text { Duration }\end{array}$ & 0.35 & 0 & 0.2 & 0.6 & 0 & 0 & 0.70 & 0.210 & 0 & 0.72 & 0.65 & 0.07 \\
\hline
\end{tabular}

Table 1

Assigned weights, beliefs and calculated probability masses for level 3attributes

$$
\beta_{1}=\frac{m_{1, I(2)}}{1-\bar{m}_{H, I(2)}}=0
$$

and $m_{H, i}=\bar{m}_{H, i}+\tilde{m}_{H, i}(\mathrm{i}=1,2 \ldots$.$) now we have$

$m_{1, I(2)}=K_{I(2)}\left(m_{1,1}, m_{1,2}+m_{l, 1}, m_{H, 2}+m_{1,2} m_{H, 1}\right)=0$

$m_{2, I(2)}=K_{I(2)}\left(m_{2,1}, m_{2,2}+m_{2,1}, m_{H, 2}+m_{2,2} m_{H, 1}\right)$

$=1.1173(0+0+0.30 * 0.65)=0.21787$

$m_{3, I(2)}=K_{I(2)}\left(m_{3,1}, m_{3,2}+m_{3,1}, m_{H, 2}+m_{3,2} m_{H, 1}\right)$

$=1.1173(0+0+0.245 * 0.70)=0.19162$

$m_{4, I(2)}=K_{I(2)}\left(m_{4,1}, m_{4,2}+m_{4,1}, m_{H, 2}+m_{4,2} m_{H, 1}\right)$

$=1.1173(0+0+0.105 * 0.70)=0.08212$

$\bar{m}_{H, I(2)}=K_{I(2)}\left\lfloor\bar{m}_{H, I(1)} \bar{m}_{H, 2}\right\rfloor=0.455$

$\tilde{m}_{H, I(2)}=K_{I(2)}\left[\tilde{m}_{H, I(1)} \tilde{m}_{H, 2}+\bar{m}_{H, I(1)} \tilde{m}_{H, 2}+\tilde{m}_{H, I(1)} \bar{m}_{H, 2}\right]$ Then the Relevant Experience of Tender1 is assessed by

$\beta_{3}=\frac{m_{3, I(2)}}{1-\bar{m}_{H, I(2)}}=\frac{0.31045}{1-0.36001}=0.48509$

$\beta_{4}=\frac{m_{4, I(2)}}{1-\bar{m}_{H, I(2)}}=\frac{0.06441}{1-0.36001}=0.10064$

$\beta_{H}=\frac{\tilde{m}_{H, I(2)}}{1-\bar{m}_{H, I(2)}}=\frac{0.03877}{1-0.36001}=0.06058$
Similarly we get

$m_{1, I(3)=0,} m_{2, I(3)}=0.226276, m_{3, I(3)}=0.310450, m_{4, I(3)}=0.06441$

$\bar{m}_{H, I(2)}=0.36001$ and

$\tilde{m}_{H, I(2)}=0.03877$

Now the combined degrees of belief are calculated by using equation as follows [4], [5], [6], [7], [8]:
$S($ Relevant Experience $)=\{($ average, 0.35356),$($ good, 0.48509$)$, (excellent,0.10064)\}

$\beta_{2}=\frac{m_{2, I(2)}}{1-\bar{m}_{H, I(2)}}=\frac{0.226276}{1-0.36001}=0.35356$

From the statement (1) we can say that Relevant Experience of

Tender 1 is assessed by evaluation grade average is $35.356 \%$, good is $48.509 \%$ and excellent is $10.064 \%$. Here we also see that the Relevant Experience is evaluated by 6.058 unassigned degree due to uncertainty.

After repeating above procedure recursively the other attributes such as past performance, technical skills, resources, management systems and price are aggregated which are shown on the Table 2 . 
After aggregating five criteria we find the assessment degree of for tender1 as follows:

$S($ Tender 1$)=\{($ poor, 0.02563$),($ average, 0.51809$)$, (good, 0.39628), (excellent, 0.39628) \}

Similarly we can generate the overall assessment of other three tenders such as Tender2, Tender3, and Tender4:

$S($ Tender 2$)=\{($ poor, 0.12104$),($ average, 0.32976$)$, (good, 0.46778), (excellent, 0.05192) \}

$S($ Tender 3$)=\{($ poor, 0.12512$),($ average, 0.45748$)$, (good, 0.30331), (excellent, 0.07598) \}

$S($ Tender 4$)=\{($ poor, 0.20271$),($ average, 0.31205$)$, (good, 0.45920), (excellent, 0) \}

Table 3

Distributed overall belief for four tenders
TABLE2

DEGREE OF MAIN CRITERIA

\begin{tabular}{|c|c|c|c|c|}
\hline \multirow{2}{*}{$\begin{array}{c}\text { General } \\
\text { attributes }\end{array}$} & \multirow[b]{2}{*}{ Tender1 } & \multirow[b]{2}{*}{ Tendre2 } & \multirow[b]{2}{*}{ Tender3 } & \multirow[b]{2}{*}{ Tender4 } \\
\hline & & & & \\
\hline \multirow{3}{*}{$\begin{array}{l}\text { Relevant } \\
\text { Experience }\end{array}$} & $\mathbf{A}(0.35356)$ & $P(0.50200)$ & $\mathbf{A}(\mathbf{0 . 1 4 3 8 3})$ & $\mathrm{A}(0.27570)$ \\
\hline & $G(0.48509)$ & $\mathrm{A}(\mathbf{0 . 1 3 0 3 4 )}$ & $G(0.69479)$ & $G(0.66648)$ \\
\hline & $\mathrm{E}(0.10064)$ & $\mathbf{E}(0.34157)$ & $\mathrm{E}(0.05904)$ & \\
\hline \multirow{4}{*}{$\begin{array}{l}\text { Past } \\
\text { Performance }\end{array}$} & & & & \\
\hline & $\mathbf{P}(0.06235)$ & $P(0.02683)$ & $\mathbf{A}(\mathbf{0 . 3 4 0 3 5 )}$ & $P(0.030103)$ \\
\hline & $\mathrm{A}(\mathbf{0 . 3 3 1 8 4})$ & $\mathbf{A}(\mathbf{0 . 7 1 9 3 8 )}$ & $G(0.63103)$ & $\mathrm{A}(0.27093)$ \\
\hline & $\mathbf{G}(\mathbf{0 . 5 1 9 7 3})$ & $\mathbf{G}(0.25377)$ & & G(0.64187) \\
\hline \multirow{4}{*}{$\begin{array}{l}\text { Technical } \\
\text { Skills }\end{array}$} & $P(0.11406)$ & $\mathbf{P}(0.23873)$ & $P(0.50086)$ & \\
\hline & $\mathrm{A}(0.14257)$ & $\mathrm{A}(0.38789)$ & $\mathrm{A}(0.14291)$ & $\mathbf{A}(0.09612)$ \\
\hline & $G(0.71484)$ & $G(0.31154)$ & $\mathbf{G}(0.22934)$ & G(0.90387) \\
\hline & & & $\mathrm{E}(0.09828)$ & \\
\hline \multirow{4}{*}{$\begin{array}{l}\text { Management } \\
\text { System }\end{array}$} & $\mathbf{A}(0.65548)$ & $\mathbf{A}(0.27578)$ & $P(0.14675)$ & $\mathbf{P}(0.51555)$ \\
\hline & $G(0.20036)$ & $G(0.61322)$ & $\mathrm{A}(0.25847)$ & $\mathrm{A}(0.12419)$ \\
\hline & $\mathbf{E}(0.08587)$ & & G(0.17778) & G()0.29930 \\
\hline & & & E(0.32419) & \\
\hline Price & $€ 230000$ & $€ 220000$ & $€ 234500$ & $€ 240000$ \\
\hline
\end{tabular}

\section{EXPERIMENTAL RESULT AND ANALYSIS}

To precisely rank the four tenders, their utilities need to be estimated. To do so, the utilities of the four individual evaluation grades need to be estimated first. The above partial rankings of alternatives could be used to formulate regression models for estimating the utilities of grades [4],[5].[6],[7],[8]. The maximum, minimum, and the average expected utility on $y$ are given by:

$$
\begin{array}{r}
u_{\text {max }}(y)=\sum_{n=1}^{N-1} \beta_{n} u\left(H_{n}\right)+\left(\beta_{N}+\beta_{H}\right) u\left(H_{N}\right) \\
u_{\text {min }}(y)=\left(\beta_{1}+\beta_{H}\right) u\left(H_{1}\right)+\sum_{n=2}^{N} \beta_{n} u\left(H_{n}\right) \\
u_{\text {avg }}(y)=\frac{u_{\text {max }}(y)-u_{\text {min }}(y)}{2} .
\end{array}
$$

If all original assessments on $y$ are complete, meaning $\beta_{H}=0$ , then $u(y)=u_{\max }(y)=u_{\text {min }}(y)=u_{a v g}(y)$. The ranking of two alternatives $a_{l}$ and $a_{k}$ is based on their utility intervals. It is said that $a_{l}$ is preferred over $a_{k}$ if and only if $u_{\text {min }}\left(y\left(a_{l}\right)\right)>u_{\max }\left(y\left(a_{k}\right)\right)$. The alternatives are indifferent if and only if $u_{\min }\left(y\left(a_{l}\right)\right)=u_{\min }\left(y\left(a_{k}\right)\right)$ and $u_{\max }\left(y\left(a_{l}\right)\right)=u_{\max }\left(y\left(a_{k}\right)\right)$.

Fig 2: Performance Evaluation for Tender2 


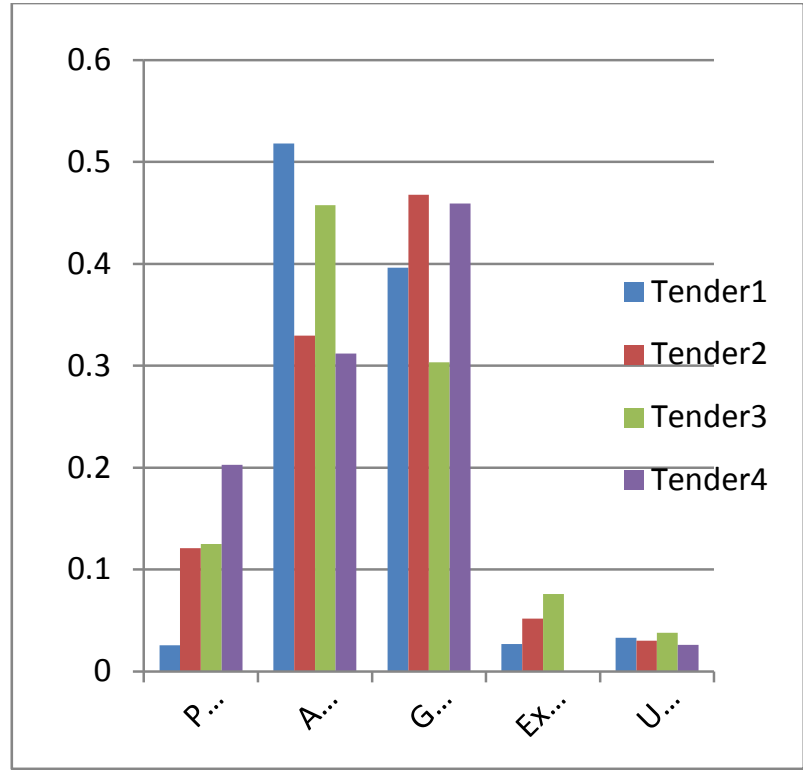

Fig. 3. Distributed Assessment of Tenders

In any other case ranking is inconclusive and not reliable. To generate reliable ranking, the quality of the original assessment needs to be improved by reducing associated incompleteness concerning $a_{l}$ and $a_{k}$.

Now using (4a)-(4c) we get the utilities as the table4.

Table 4

Utilities on tender evaluation

\begin{tabular}{|l|l|l|l|l|}
\hline & $U_{\min }$ & $U_{\max }$ & $U_{\text {avg }}$ & Rank \\
\hline Tender1 & 0.4640 & 0.497 & 0.4805 & 2 \\
\hline Tender2 & 0.4737 & 0.5031 & 0.4884 & 1 \\
\hline Tender3 & 0.4307 & 0.4687 & 0.4497 & 3 \\
\hline Tender4 & 0.4102 & 0.4362 & 0.4232 & 4 \\
& & & & \\
\hline
\end{tabular}

The ranking of the four tenders is stated as follows:Tender2 $>$ Tender $1>$ Tender3 $>$ Tender 4

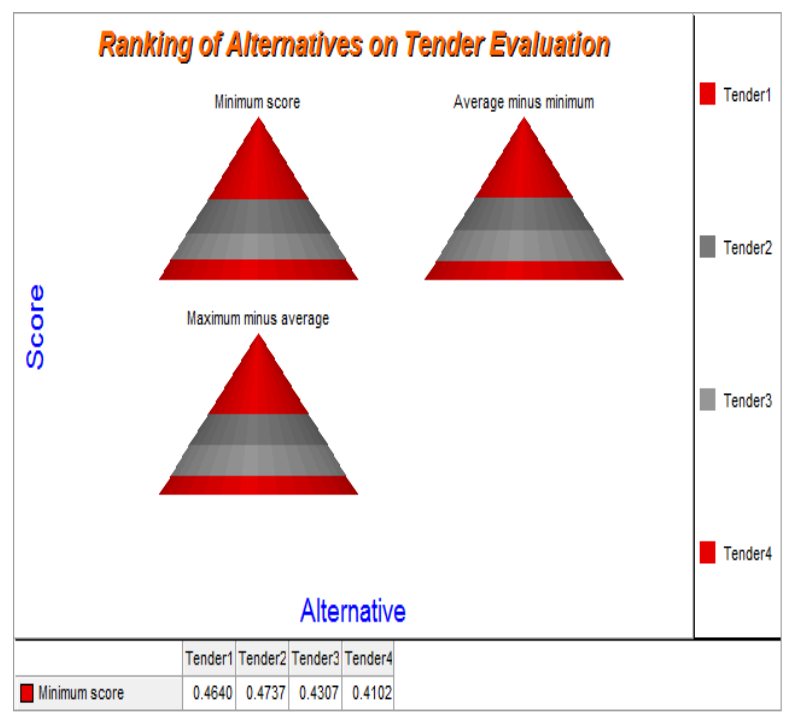

Fig 4. Ranking Of Four Tenders

\section{CONCLUSION}

Tender evaluation is complex and fragmented. Without a proper and accurate method for evaluating the tender, the performance of the project will be affected, thereby denying the client value for money. In order to ensure the completion of the project successfully, the client must evaluate the tender in an accurate and transparent way. The ER framework as presented in this paper will help to improve the quality of tender evaluation process. The reason for this is that the ER approach is capable of handling incomplete, imprecise and vague information as shown in the previous section. Eventually, this will help DMs to reach robust decisions even in the presence of incomplete data.

\section{REFERENCES}

[1] Guidelines on tender Evaluation using weighted criteria for Building Works and Services, Tasmania, Department Of Treasury And Finance, version 2.0, pp.1-12, 2006.

[2] Standard Tender Documents, Procurement of Works User Guide, European Bank for Reconstruction and development, pp. 1-122, August 2010.

[3] J. B. Yang and M. G. Singh, "An Evidential Reasoning Approach for Multiple Attribute Decision Making with Uncertainty," IEEE Trans. Syst.,Man, Cybern., vol. 24, no. 1, pp. 1-4, 1994.

[4] J. B. Yang and D. L. Xu, "On the Evidential Reasoning Algorithm for Multiple Attribute Decision Analysis with Uncertainty," IEEE Trans. Syst., Man, Cybern. A, vol. 32, pp. 289-304, May 2002.

[5] J. B. Yang and D. L. Xu, "Nonlinear Information Aggregation via Evidential Reasoning in Multiattribute Decision Analysis Under Uncertainty," IEEE Trans. Syst., Man, Cybern. A, vol. 32, no. 4, pp. 376-393, May 2002.

[6] J. B. Yang, "Rule and Utility Based Evidential Reasoning Approach for Multiple Attribute Decision Analysis Under Uncertainty," Eur. J. Oper.Res., vol. 131, no. 1, pp. 31-61, 2001.

[7] D. L. Xu, "Assessment of Nuclear Waste Repository Options Using the Er Approach," Int. J. of I T \& DM vol. 8, no. 3, pp. 581-607, 2009.

[8] P. Gustafsson, R. Lagerström, P. Närman, and M. Simonsson , "The Ics Dempster-Shafer how to ," unpublished

[9] Y.Wang, J. B. Yang, and D. L. Xu, "Environmental Impact Assessment using the Evidential Reasoning Approach," Eur. J. Oper.Res., vol. 174, pp. 1885-1913, 2005.

[10] M. Soenmez, J. B. Yang \& G. D. Holt, "Addressing the contractor selection problem using an evidential reasoning approach," Blackwell Science Ltd, Engineering, Construction and Architectural Management, vol. 8, no. 3, pp. 198-210, 2001.

[11] M. Soenmez, J. B. Yang ,G. D. Holt \& G.Graham, "Applying Evidential Reasoning to Prequalifying Construction Contractors," Journal of Management in Engineering, vol. 18, no. 3, pp. 111-119,July 2002.

[12] G.Graham \& G. Hardakder " Contractor Evaluation in the Aerospace Industry using the Evidential Reasoning Approach," Journal of Research in Marketing \& Entrepreneurship, vol. 3, no. 3, pp. 162-173,2001. 
[13] L.E.Clarker "Factors in the Selection of Contractors for," University of Southern Queensland, Faculty of Engineering and Surveying ,pp.1-172, November,2007.

[14] Schapper, Paul R (2006). "An Analytical Framework for the Management and Reform of Public Procurement". Journal of Public Procurement - Vol. 6 Nbr. 1/2. PrAcademics Press
[15] Singer, Marcos (2009). "Does E-Procurement Save the State Money?'Journal of Public Procurement - Vol. 9 Nbr. 1. PrAcademics Press.

[16] Governing Principles of e-Government procurement Central Procurement Technical Unit (CPTU),Implementation Monitoring and Evaluation Division, Government of The People's Republic of Bangladesh. 